\title{
Vibrations of Circular Plates Resting on Elastic Foundation with Elastically Restrained Edge Against Translation
}

\author{
L.B. Rao ${ }^{a}{ }^{*}$ and C.K. Rao ${ }^{b}$ \\ a School of Mechanical and Building Sciences, VIT University, Chennai Campus, Vandalur-Kelambakkam Road, Chennai- \\ 600127, Tamil Nadu, India. \\ ${ }^{b}$ Department of Mechanical Engineering, School of Engineering, Chaudari guda, Korremulla ' $X$ ' Roads, Near Narapalli, \\ Ghatkesar (M), Hyderabad-500 088, India.
}

Received 6 July 2016; Accepted 26 January 2017

\begin{abstract}
The present paper deals with exact solutions for the free vibration characteristics of thin circular plates resting on Winkler-type elastic foundation based on the classical plate theory elastically restrained against translation. Parametric investigations are carried out for estimating the influence of edge restraint against translation and stiffness of the elastic foundation on the natural frequencies of circular plates. The elastic edge restraint against translation and the presence of elastic foundation has been found to have a profound influence on vibration characteristics of the circular plate undergoing free transverse vibrations. Computations are carried out for natural frequencies of vibrations for varying values of translational stiffness ratio and stiffness parameter of Winkler-type foundation. Results are presented for twelve modes of vibration both in tabular and graphical form for use in the design. Extensive data is tabulated so that pertinent conclusions can be arrived at on the influence of translational edge restraint and the foundation stiffness ratio of the Winkler foundation on the natural frequencies of uniform isotropic circular plates.
\end{abstract}

Keywords: Plate; Frequency; Elastic edge; Translational stiffness; Elastic foundation.

\footnotetext{
اهتزازات الالواح الدائرية المثبتة على قاعدة مرنة مع حافة مقيدة المرونة اثتاء الحركة لوكافارابو بهاسكارا راو '، *، تشيلابيلا كامسوارا راوبه

الملخص : تتاول الدراسة البحثية الحلول الصحيحة لخصائص الاهنزازات الحرة للالواح الدائرية الرقيقة المثبتة على قاعدة مرنة من نوع وينكلر ذات حافة مقيدة المرونة اثناء الحركة بهوجب نظرية الالواح التقليدية. تم إجراء ابحاث معاملية (بارامترية) لتقديرمدى تأثير تقييد الحافة اثناء الحركة وصلابة القاعدة المرنة على الترددات الطبيعية للألواح الدائرية. و توصل البحث الى أن الحافة مقيدة المرونة أثناء عملية الحركة مع وجود القاعدة المرنة لها تأثير كبير على خصائص اهتزاز

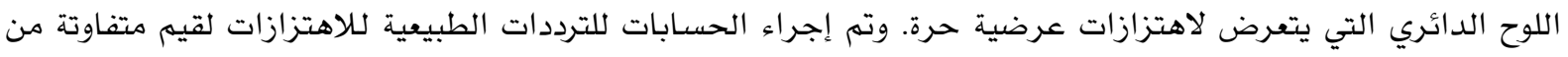
معدل الصلابة المتعدية ومعامل صلابة القاعدة من نوع وينكلر. و قدم البحث النتائج لاثني عشر نهطا من أنماط الاهتزازات

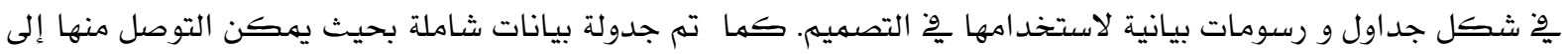
استتاجات ذات صلة بتأثير تقييد الحافة المتقلة ونسبة صلابة القاعدة من نوع وينكلر على الترددات الطبيعية للوحات الدائرية المتماثلة الموحدة. الكلمات المفتاحية : لوح، التردد ،حافة مرنة، صلابة متتقلة، قاعدة مرنة
}

* Corresponding author's e-mail: bhaskarbabu_20@yahoo.com 


\section{Nomenclature}

$\begin{array}{ll}h & \text { Thickness of a plate, } \mathrm{mm} \\ v & \text { Radius of a plate, } \mathrm{mm} \\ E & \text { Poisson's ratio } \\ \rho & \text { Young's modulus, } \mathrm{N} / \mathrm{mm}^{2} \\ W(r, \theta) & \text { Density of a material, } \mathrm{kg} / \mathrm{mm}^{3} \\ D & \text { Transverse deflection of the plate, } \mathrm{mm} \\ K_{T} & \text { Translational spring stiffness, N/mm } \\ K_{w} & \text { Stiffness of Winkler foundation, } \mathrm{N} / \mathrm{mm}{ }^{2} / \mathrm{mm} \\ T & \text { Translational spring stiffness ratio } \\ \xi_{m n} & \text { Foundation stiffness ratio } \\ \omega_{m n} & \text { Natural frequency, rad/sec } \\ \lambda_{m n} & \end{array}$

$\lambda_{m n}^{*}$

Eigenvalue with Winkler foundation, cycles/sec $m, n$ positive integers corresponding to the number of concentric circles and nodal diameters in each flexural mode. 


\section{Introduction}

Circular plates resting on elastic foundation have a wide range of applications in the static and dynamic design of linear/nonlinear vibration absorbers, dynamic exciters, telephone receiver diaphragms, computer discs, printed circuit boards etc. (Leissa 1969). Due to the essential use of vibration data in the computation of stresses in such structures, reliable prediction of vibration data is of great importance. In view of its importance in engineering design, the problem of vibration of circular plates on elastic foundation has attracted the focus and attention of many researchers.

Some of the recent studies have reinstated the classical approach efficiency in analyzing the vibrations of variety of structures. Circular plate problems allow for significant simplification in view of their symmetry, but still many difficulties arise when the plate boundary conditions become complex involving linear and rotational restraints. A recent review of literature shows that very few studies exist on the study of circular plates resting on elastic foundations. Wang and Wang (2003), who observed the switching between axisymmetric and asymmetric vibration modes, have recently investigated the effect of internal elastic translational supports.

The vibration characteristics of plates resting on an elastic medium are different from those of the plates supported only on the boundary. Leissa (1993) discussed the vibration of a plate supported laterally by an elastic foundation. Leissa deduced that the effect of Winkler foundation merely increases the square of the plate natural frequency by a constant. Salari et al. (1987) speculated the same conclusion. Ascione and Grimaldi (1984) studied unilateral frictionless contact between a circular plate and a Winkler foundation using a variational formulation. Leissa (1969), who tabulated a frequency parameter for four vibration modes of a simply supported circular plate with varying rotational stiffness, presented one of the earliest formulations of this problem. Kang and Kim (1996) presented an extensive review of the modal properties of the elastically restrained beams and plates.

Zheng and Zhou (1988) studied the large deflection of a circular plate resting on Winkler foundation. Ghosh (1997) studied the free and forced vibration of circular plates on Winkler foundation by an exact analytical method. (Chang and Wickert (2001); Kim et al. (2001) and Tseng and Wickert (1994) studied the dynamic characteristics of bolted flange connections involving circular plates displaying beating type of repeat frequencies and typical mode shapes of vibration. Bolted flange connections are practically the best examples for the elastically restrained boundary conditions of circular plates on partial or continuous Winkler type elastic foundation.

The most general soil model used in practical applications is the Winkler (1867) model in which the elastic medium below a structure is represented by a system of identical but mutually independent elastic linear springs. Recent investigations have reiterated the efficiency of the classical approach (Soedel 1993) in analyzing the behavior of structures under vibrations. There are other works (Weisman 1970; Dempsey et al. 1984; Celep et al. 1988) dealing with the study of plates on a Winkler foundation. In general, those dealing with vibrating plates, shells and beams are concerned with the determination of eigenvalues and mode shapes (Leissa 1969).

A good number of studies was conduced (Wang and Lin 1996; Kim and Kim 2001; Yayli et al. 2014) using the method of Fourier series for estimating the frequencies of beams with generally restrained end conditions including the effect of elastic soil foundation. The method includes the use of Stoke's transformation in suitably modifying the complex boundary conditions. Very much similar to the dynamic stiffness matrix approach, the elements of the matrix involving infinite Fourier series are explicitly obtained in these studies. The determinant of this matrix for each case considered leads to the frequency equation and the same can be solved using well known numerical methods. The results obtained for various elastically restrained beam cases in these studies tallied well with those available in the literature establishing the efficiency of this method.

In view of the necessity of using complex combinations of rotational and translational springs at the circular plate boundary to suitably simulate the practical non-classical boundary connections being adopted in a wide range of industrial applications (Bhaskara Rao et al. 2009; Bhaskara Rao et al. 2010; Lokavarapu and Chellapilla 2013; Bhaskara Rao et al. 2015; Lokavarapu et al. 2015; Rao et al. 2016), the use of exact method of solution becomes imperative 
and hence the same is adopted in this paper. Even though the method adopted here is classical, the particular case of vibration of elastically restrained circular plate resting on elastic foundation considered here is not addressed within the available literature.

Utilizing the classical plate theory, this paper deals with an exact method of solution for the analysis of thin circular plate free transverse vibrations that is elastically restrained against translation and resting on Winkler-type elastic foundation. For estimating the influence of edge restraint against the elastic foundation translation and stiffness on circular plates natural frequencies, parametric investigations are carried out by varying the values of elastic edge restraint stiffness against the elastic foundation translation and stiffness. The results obtained on natural frequencies of vibration clearly show that the vibration characteristics of the circular plate undergoing free transverse vibrations are found to be profoundly influenced by these variations. Computations are carried out for natural frequencies of vibrations for varying values of translational stiffness ratio and stiffness parameter of Winkler-type foundation. The results that are presented for twelve modes of vibration both in tabular and graphical forms are believed to be quite useful for designers in this area.

\section{Mathematical Formulation of the System}

The considered elastic thin circular plate is supported on a Winkler foundation as shown in Fig. 1. In the classical plate theory (Leissa 1969), the following fourth order differential equation describes free flexural vibrations of a thin circular uniform plate:

$$
\text { D. } \nabla^{4} w(r, \theta, t)+\rho h \partial^{2} w(r, \theta, t) / \partial t^{2}=0
$$

where $D=E h^{3} / 12\left(1-v^{2}\right)$ is the flexural rigidity of a plate and $a, h, \rho, E, v$ are the plate's radius, thickness, density, Young's modulus and Poisson's ratio, respectively.

The homogeneous equation for Kirchhoff's plate on one parameter elastic foundation is given by the following equation:

$$
\begin{gathered}
\text { D. } \nabla^{4} \mathrm{w}(\mathrm{r}, \theta, \mathrm{t})+\mathrm{K}_{\mathrm{W}} \mathrm{w}(\mathrm{r}, \theta, \mathrm{t})+ \\
\rho h \partial^{2} \mathrm{w}(\mathrm{r}, \theta, \mathrm{t}) / \partial \mathrm{t}^{2}=0
\end{gathered}
$$

Displacement in (2) can be presented as a combination of spatial and time dependent components as follows:

Let $w(r, \theta, t)=W(r, \theta) e^{i \omega t}$

Now substitute (3) in (2)

$D \cdot \nabla^{4} W(r, \theta)+\left(K_{w}-\rho h \omega^{2}\right) \cdot W(r, \theta)=0$

The solution of the equation takes the following form

$W_{m n}(r, \theta)=A_{m n}\left[\begin{array}{l}J_{n}\left(\frac{\lambda_{m n} r}{a}\right)+C_{m n} I_{n} \\ \left(\frac{\lambda_{m n} r}{a}\right)\end{array}\right] \cdot \cos n \theta, \mathrm{n}>0$

where $A_{m n}$ and $C_{m n}$ are constants, $J_{n}$ is Bessel function of the first kind of first order and $I_{n}$ is modified Bessel function of the first kind of first order, indexes $m$ and $n$ are positive integers and correspond to the number of concentric circles and nodal diameters in each flexural mode. Considering an elastically supported plate as shown in Fig. 1, boundary conditions can be formulated at $r=a$, in terms of translational stiffness $\left(K_{T}\right)$ as follows:

$\mathrm{M}_{\mathrm{r}}(\mathrm{a}, \theta)=0$

$V_{r}(a, \theta)=K_{T} W(a, \theta)$

where the Kelvin-Kirchhoff and bending moment are defined as follows:

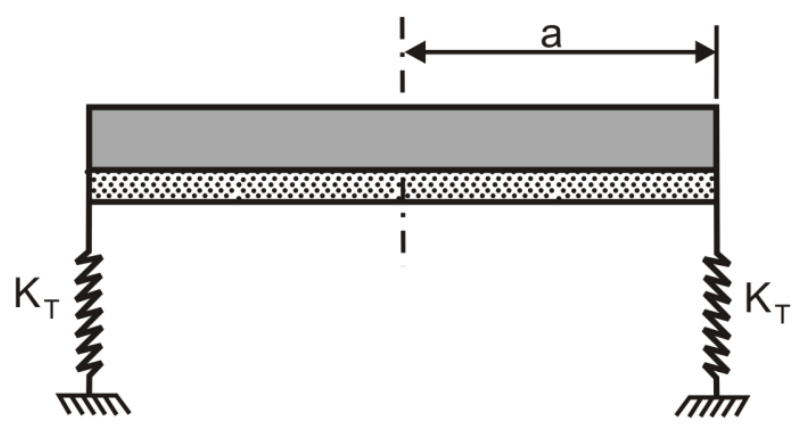

Figure 1. A thin circular plate with translational elastic edge restraint and supported on elastic foundation. 


$$
\begin{aligned}
& M_{r}(a, \theta)=-D \cdot\left[\begin{array}{l}
\frac{\partial^{2} W(a, \theta)}{\partial r^{2}}+v\left(\begin{array}{l}
\frac{1}{r} \frac{\partial W(a, \theta)}{\partial r} \\
\left.+\frac{1}{r^{2}} \frac{\partial^{2} W(a, \theta)}{\partial \theta^{2}}\right)
\end{array}\right] \\
V_{r}(a, \theta)=-D \cdot\left[\left(\frac{\frac{\partial}{\partial r} \nabla^{2} W(a, \theta)+(1-v) \frac{1}{r} \frac{\partial}{\partial \theta}}{r} \frac{\partial^{2} W(a, \theta)}{\partial r \partial \theta}-\frac{1}{r^{2}} \frac{\partial W(a, \theta)}{\partial \theta}\right)\right.
\end{array}\right]
\end{aligned}
$$

By applying Eqs. (6) and (8), we obtain the following equation

$$
\left[\frac{\partial^{2} W(a, \theta)}{\partial r^{2}}+v\left(\frac{1}{r} \frac{\partial W(a, \theta)}{\partial r}+\frac{1}{r^{2}} \frac{\partial^{2} W(a, \theta)}{\partial \theta^{2}}\right)\right]=0
$$

From Eqs. (5) and (10), we derive the following equation

$$
C_{m n}=\frac{R_{m n}-\frac{2 Q_{m n}}{\lambda_{m n}}-\left[3+\frac{4+4(2-v) n^{2}}{\lambda_{m n}}\right] P_{m n}-\left[\frac{8(3-v) n^{2}}{\lambda^{3}}-\frac{4}{\lambda_{m n}}-\frac{8}{\lambda_{m n}{ }^{3}} T\right] J_{n}\left(\lambda_{m n}\right)}{U_{m n}+\frac{2 T_{m n}}{\lambda_{m n}}+\left[3-\frac{4-4(2-v) n^{2}}{\lambda_{m n}}\right] S_{m n}+\left[\frac{8(3-v) n^{2}}{\lambda_{m n}}+\frac{4}{\lambda_{m n}}-\frac{8}{\lambda_{m n}{ }^{3}} T\right] I_{n}\left(\lambda_{m n}\right)}
$$

where, $T=\frac{a^{3} K_{T}}{D}$

$$
\begin{aligned}
& P_{m n}=J_{n+1}\left(\lambda_{m n}\right)-J_{n-1}\left(\lambda_{m n}\right) ; Q_{m n}=J_{n+2}\left(\lambda_{m n}\right)+J_{n-2}\left(\lambda_{m n}\right) ; R_{m n}=J_{n+3}\left(\lambda_{m n}\right)-J_{n-3}\left(\lambda_{m n}\right) ; \\
& S_{m n}=I_{n+1}\left(\lambda_{m n}\right)+I_{n-1}\left(\lambda_{m n}\right) ; T_{m n}=I_{n+2}\left(\lambda_{m n}\right)+I_{n-2}\left(\lambda_{m n}\right) ; U_{m n}=I_{n+3}\left(\lambda_{m n}\right)+I_{n-3}\left(\lambda_{m n}\right) ;
\end{aligned}
$$

If $K_{T} \rightarrow \infty$ then this case becomes a simply supported boundary condition as shown in Fig. 2. The frequency equation can be calculated From Eqs. (11) and (13), which allows determining eigenvalues $\lambda_{m n}$. The mode shape parameters $C_{m n}$ can be determined corresponding to these eigenvalues by using either Eq. (11) or Eq. (13). The amplitude of each vibration mode in Eq. (5) is set by the normalization constant $A_{m n}$ determined from the following condition.

$$
\int_{0}^{2 \pi} \int_{0}^{a} W_{m n}(r, \theta) . W_{p q}(r, \theta) r d r d \theta=M_{m n} \delta_{m p} \delta_{n q}
$$

where, $M_{m n}$ is a mass of the plate,

$$
\delta_{m p}=\delta_{n q}=1 \text { if } m=p, n=q \text { and } \delta_{m p} \delta_{n q}=
$$

0 if $m \neq p$ or $n \neq q$.

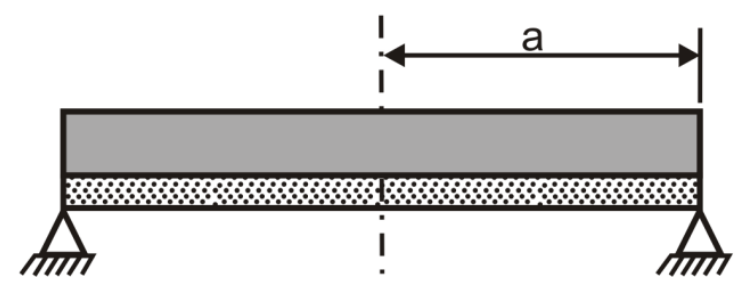

Figure 2. A simply supported thin circular plate resting on elastic foundation. 
The normalization constant $A_{m n}$ can be derived using Eqs. (5) and (14) as given below:

$A_{m n}=\left[\frac{1}{\pi a^{2}} \cdot \iint_{0}^{2 \pi} \int\left(\begin{array}{l}0 \\ 0\end{array}\left(\begin{array}{l}J_{n}\left(\frac{\lambda_{m n} r}{a}\right)+ \\ C_{m n} \cdot I_{n}\left(\frac{\lambda_{m n} r}{a}\right)\end{array}\right) \cdot \cos n \theta\right)^{2} r d r d \theta\right]^{-1}$

In Eq (4), the natural frequency is defined as

$\omega_{m n}=\left(\frac{\lambda_{m n}^{2}}{a^{2}}\right) \sqrt{\left(\frac{D}{\rho h}\right)}$

It is clear from Eq. (16) that the natural frequency parameter $\omega_{m n}$ is dependent on the plate radius ' $a$ '.

From Eq. (16) we can express

$\lambda_{m n}{ }^{4}=\frac{\rho h a^{4} \omega_{m n}^{2}}{D}$

$\lambda_{m n}{ }^{* 4}=\lambda_{m n}{ }^{4}+\xi^{2}$

where $\xi^{2}=\frac{K_{w} a^{4}}{D}$

$\lambda_{m n}{ }^{*}=\left[\lambda_{m n}{ }^{4}+\xi^{2}\right]^{\frac{1}{4}}$

\section{Solution}

Using Matlab programming, computer software with symbolic capabilities, solves the above set of equations. The program determines eigenvalues $\left(\lambda_{m n}{ }^{*}\right)$, for a given range of boundary conditions. The boundary's linear translational non-dimensional restraint parameter can be defined as follows:

$$
\begin{aligned}
& T=\frac{K_{T} a^{3}}{D} \\
& \xi^{2}=\frac{K_{w} a^{4}}{D}
\end{aligned}
$$

The following represent the input parameters to the program; (i) Translational stiffness ratio $(T)$; (ii) Foundation ratio ( $\xi$ ); (iii) Poisson's ratio ( $v$ ); (iv) Upper bound for eigenvalues $(N)$; (v) Suggested accuracy for eigenvalues $(d)$; (vi) Number of mode shape parameters $(n)$; The program finds eigenvalues $\lambda_{m n}{ }^{*}$ by using Matlab root finding function.

\section{Results and Discussion}

The code developed is used to determine eigenvalues of any set or range of translational and foundation constraints. This code is also implemented for various plate materials by adjusting Poisson's ratio. Such a wide range of results is not available in the literature. The eigenvalues for the plate edge, which is elastically restrained against translation and fully resting on the elastic foundation, at various values of the translational stiffness ratios, are computed and the results are given in Table 1. The effects of the translational stiffness ratios are plotted in Fig. 3. As seen from Fig. 3, eigenvalues increase with an increment in the translational stiffness ratio, and the plates become unstable in the region when the translational stiffness ratio exceeds a certain value. Twelve vibration modes are presented in Fig. 3. The smoothened stepped variation is observed in Fig. 3. The stepped region increases with increase in translational stiffness ratio and vibration modes. The location of the stepped region with respect to $T$ changed gradually from the range of $0.01526^{\dagger}[9.9997] \ddagger-5587.5316$ [10] to 16.62296 [14.6739] - 611824.96917 [16.75055]. Here t.represents translational stiffness ratio and $\ddagger$ represents Eigen values throughout the text. Here the value in the bracket represents eigenvalue. The simply supported boundary conditions (Fig. 2) could be accounted for by setting $\left(K_{T} \rightarrow \infty\right)$ shown in Fig. 1. The frequency in this case is 2.23175 and this is in good agreement with the results published by Wang (2005). Another result, considered for comparison, is from Rao and Rao (2009) on a study of the case of vibrations of elastically restrained circular plates supported on partial Winkler foundation. When the 
Table 1. Eigenvalues for different Translational stiffness ratio for $\xi=100 \& v=0.33$.

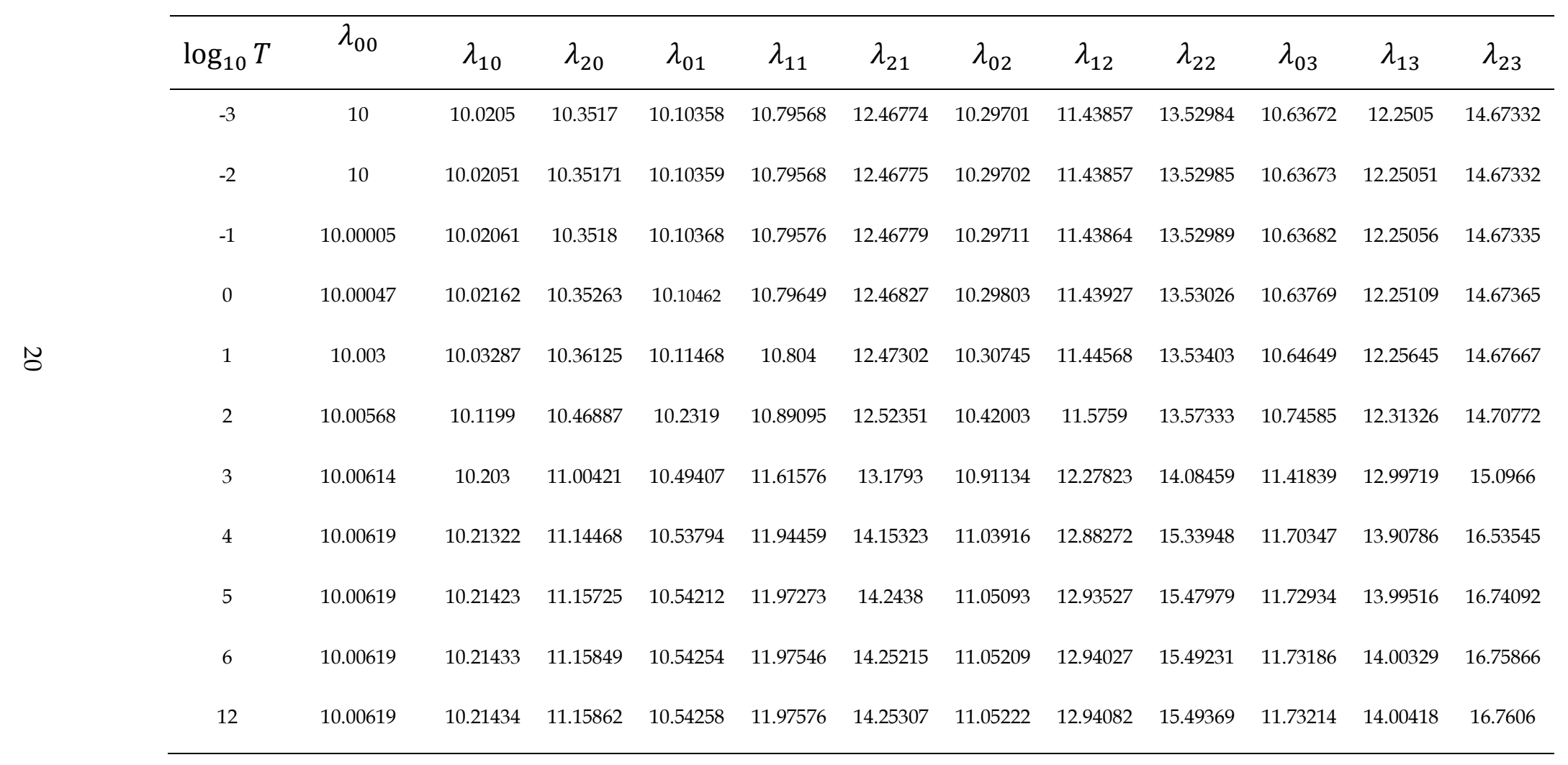


Table 2. Eigenvalues for different Foundation stiffness ratio for $T=100 \& v=0.33$.

\begin{tabular}{cccccccccccccc}
\hline $\begin{array}{c}\log _{10} \\
\zeta\end{array}$ & $\lambda_{00}$ & $\lambda_{10}$ & $\lambda_{20}$ & $\lambda_{01}$ & $\lambda_{11}$ & $\lambda_{21}$ & $\lambda_{02}$ & $\lambda_{12}$ & $\lambda_{22}$ & $\lambda_{03}$ & $\lambda_{13}$ & $\lambda_{23}$ \\
\hline-3 & 2.18341 & 4.70075 & 6.69703 & 5.56683 & 7.98678 & 10.99197 & 6.50356 & 9.33292 & 12.43922 & 7.59879 & 10.67534 & 13.84974 \\
-2 & 2.18341 & 4.70075 & 6.69703 & 5.56683 & 7.98678 & 10.99197 & 6.50356 & 9.33292 & 12.43922 & 7.59879 & 10.67534 & 13.84973 \\
-1 & 2.18365 & 4.70077 & 6.69704 & 5.56684 & 7.98679 & 10.99197 & 6.50357 & 9.33292 & 12.43922 & 7.59879 & 10.67535 & 13.84974 \\
0 & 2.20704 & 4.70315 & 6.69786 & 5.56827 & 7.98727 & 10.99216 & 6.50447 & 9.33323 & 12.43935 & 7.59936 & 10.67555 & 13.84983 \\
1 & 3.3284 & 4.92488 & 6.77875 & 5.7064 & 8.03541 & 11.01074 & 6.5926 & 9.36352 & 12.45218 & 7.65514 & 10.69583 & 13.84914 \\
2 & 10.00568 & 10.1199 & 10.46887 & 10.2319 & 10.89095 & 12.52351 & 10.42003 & 11.5159 & 13.57333 & 10.74585 & 12.31326 & 14.70772 \\
3 & 31.62296 & 31.62664 & 31.63867 & 31.63037 & 31.6549 & 31.73756 & 31.63691 & 31.68259 & 31.81038 & 31.6491 & 31.72496 & 31.90972 \\
\hline
\end{tabular}

Table 3. Eigenvalues for different Translation and Foundation stiffness ratios for $v=0.33$.

\begin{tabular}{|c|c|c|c|c|c|c|c|c|c|c|c|c|}
\hline $\begin{array}{c}\log _{10} \xi \\
\& \\
\log _{10} T\end{array}$ & $\lambda_{00}$ & $\lambda_{10}$ & $\lambda_{20}$ & $\lambda_{01}$ & $\lambda_{11}$ & $\lambda_{21}$ & $\lambda_{02}$ & $\lambda_{12}$ & $\lambda_{22}$ & $\lambda_{03}$ & $\lambda_{13}$ & $\lambda_{23}$ \\
\hline-3 & 0.2115 & 3.0115 & 6.2054 & 4.52915 & $\begin{array}{l}7.73687 \\
\end{array}$ & $\begin{array}{l}10.9091 \\
\end{array}$ & 5.93655 & 9.18564 & 12.3826 & 7.27469 & 10.57846 & 13.80849 \\
\hline-2 & 0.37648 & 3.01187 & 6.20544 & 4.52925 & 7.73689 & 10.90911 & 5.93659 & 9.18566 & 12.38261 & 7.27471 & 10.57846 & 13.8085 \\
\hline-1 & 0.67602 & 3.0156 & 6.20584 & 4.53032 & 7.73709 & 10.90918 & 5.93708 & 9.18578 & 12.38266 & 7.27499 & 10.57855 & 13.80854 \\
\hline 0 & 1.30374 & 3.067 & 6.21074 & 4.54336 & 7.73963 & 10.91008 & 5.94302 & 9.18733 & 12.38328 & 7.27834 & 10.57959 & 13.80899 \\
\hline 1 & 3.25317 & 3.90325 & 6.34932 & 4.87899 & 7.81237 & 10.93614 & 6.10341 & 9.23131 & 12.40119 & 7.36838 & 10.60869 & 13.82199 \\
\hline 2 & 10.00568 & 10.1199 & 10.46887 & 10.2319 & 10.89095 & 12.52351 & 10.42003 & 11.5152 & 13.57333 & 10.74585 & 12.31326 & 14.70772 \\
\hline 3 & 31.62297 & 31.62939 & 31.65958 & 31.63958 & 31.68744 & 31.78104 & 31.65573 & 31.72292 & 31.85232 & 31.67796 & 31.76831 & 31.94926 \\
\hline
\end{tabular}


support position is in full span, which means that when $b=1$, the case becomes a circular plate having full foundation support with elastically restrained edge against translation. For this case, the frequency is 2.1834 and that is in good agreement with the frequency of 2.18341 obtained from the present study.

The eigenvalues at various values of the foundation stiffness ratios for $T=100 \& v=0.33$ are computed and the results are given in Table 2 . The effects of the foundation stiffness ratio on eigenvalues are plotted in Fig. 4. As seen from Fig. 4, the eigenvalue increases with increase in the foundation stiffness ratio, and the plate becomes stiffer and stronger as the value of foundation stiffness becomes greater than $10^{2}$. As seen from the Tables 1 and 2, the influence of foundation stiffness ratio on eigenvalue is relatively greater than that of the translation stiffness ratio in increasing the overall natural frequencies of the plate support system. As seen from Fig. 4, for all the modes considered here, up to a value of 10 the eigenvalues stay constant and beyond this value all the curves tend to converge to a constant eigenvalue as the foundation stiffness ratio increases up to $10^{3}$. The convergence starts from 1.07897 [2.0325779] and continues up to a constant value of 9.63274 [13.84796].

The eigenvalues at various values of the translational stiffness ratios and foundation stiffness ratios are computed and the results are given in Table 3. The effects of the translation and foundation stiffness ratios on eigenvalues are clearly observed in Fig. 5, eigenvalues increases with an increment in both the translational and foundation stiffness ratios. As observed from the Table 1 and 3, the influence of foundation stiffness ratio on eigenvalue is more predominant than that of translation stiffness ratio alone. From the results presented in Tables 1 and 3, we can see that the influence of foundation stiffness ratio on eigenvalues is more predominant than that of translation stiffness ratio. From the results given in Tables 1 to 3 , one can easily find that the eigenvalues become lower for lower values of foundation and translation stiffness ratios. As seen from Fig. 5, all the curves are stable up to a certain region beyond which the curves tend to converge for increasing values of translation and foundation stiffness ratios.

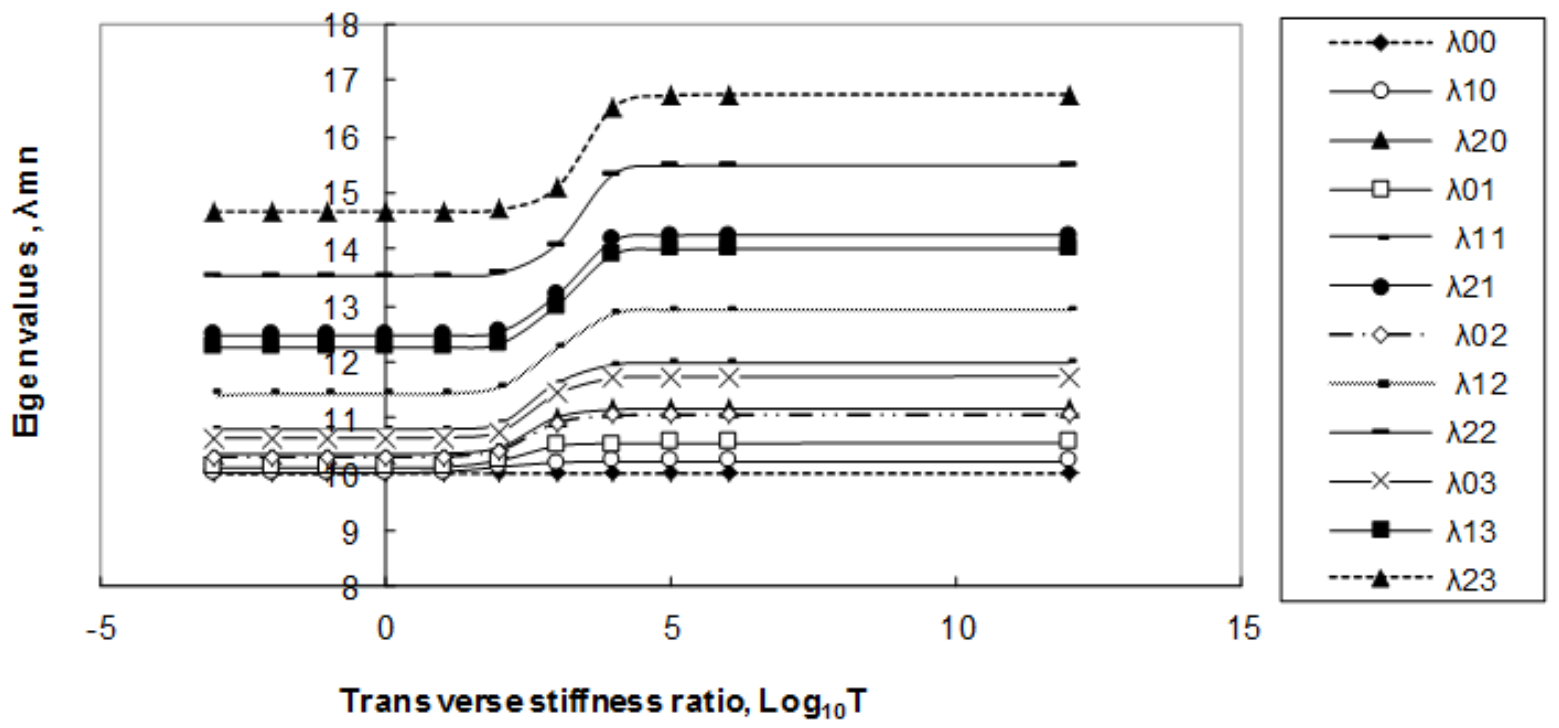

Figure 3. Effect of translational stiffness ratio $T$ on eigenvalues, $\lambda_{m n}$. 


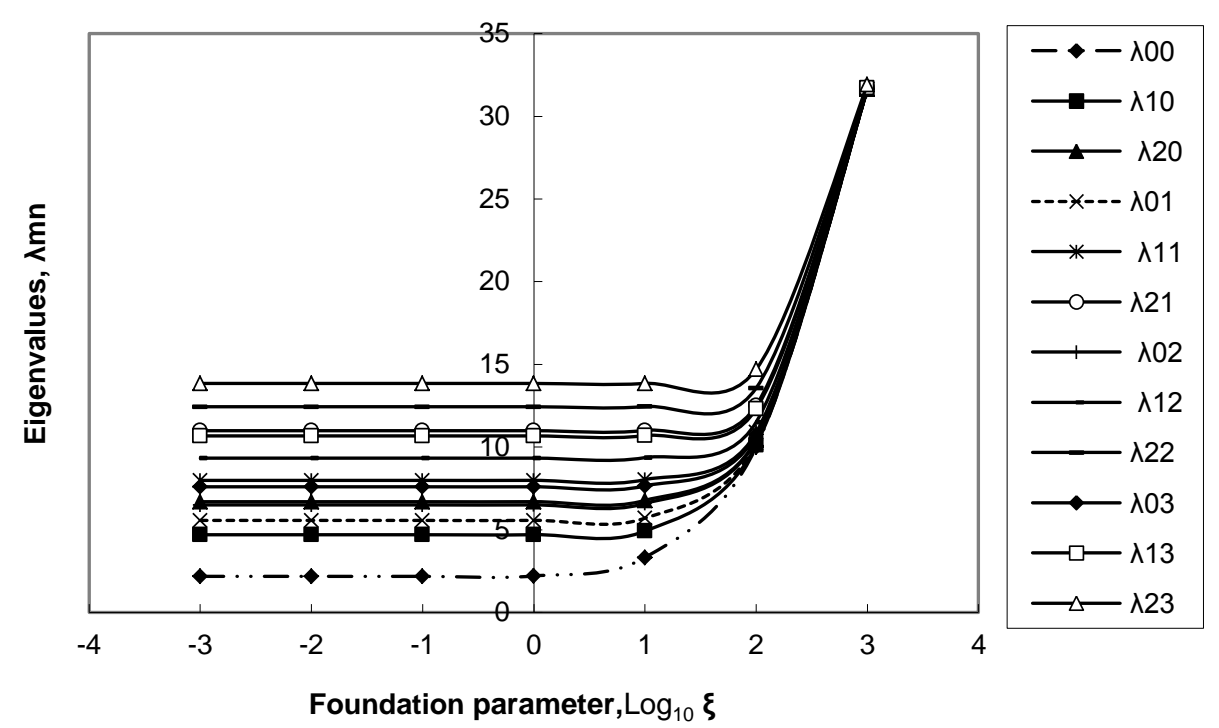

Figure 4. Effect of foundation stiffness ratio, $\xi$ on eigenvalues, $\lambda_{m n}$.

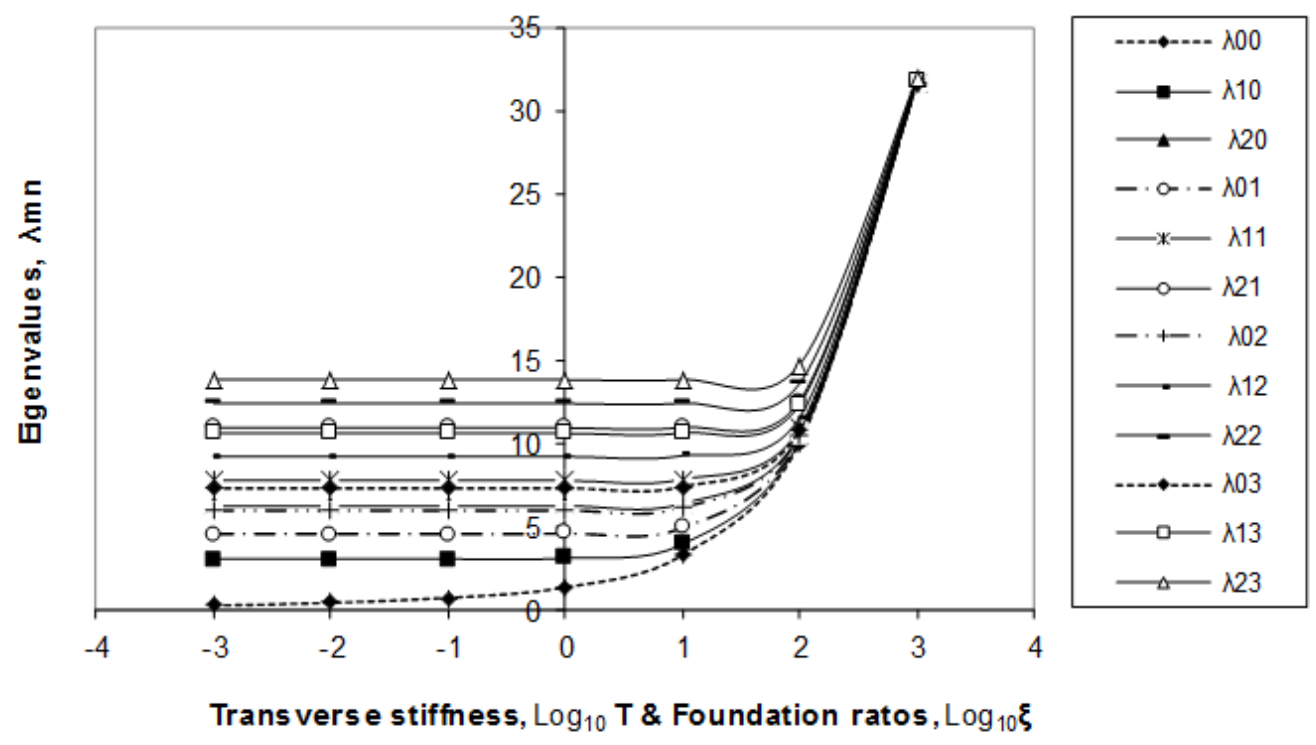

Figure 5. Effect of translational, $T$ and foundation, $\xi$ stiffness ratios on eigenvalues, $\lambda_{m n}$.

Table 4. Eigenvalues for different Poisson ratios.

\begin{tabular}{lccccc}
\hline $\mathbf{v}$ & $T=\xi=1000$ & $T=100, \xi=10$ & $T=10, \xi=1000$ & $T=1, \xi=10$ & $T=50, \xi=50$ \\
\hline 0 & 31.62925 & 4.92456 & 10.03027 & 3.62553 & 7.28924 \\
0.1 & 31.62929 & 4.92466 & 10.03111 & 3.64904 & 7.2896 \\
0.2 & 31.62934 & 4.92476 & 10.0319 & 3.6708 & 7.28993 \\
0.3 & 31.62938 & 4.92485 & 10.03265 & 3.69097 & 7.29025 \\
0.4 & 31.62942 & 4.92494 & 10.03336 & 3.70974 & 7.29056 \\
\hline
\end{tabular}




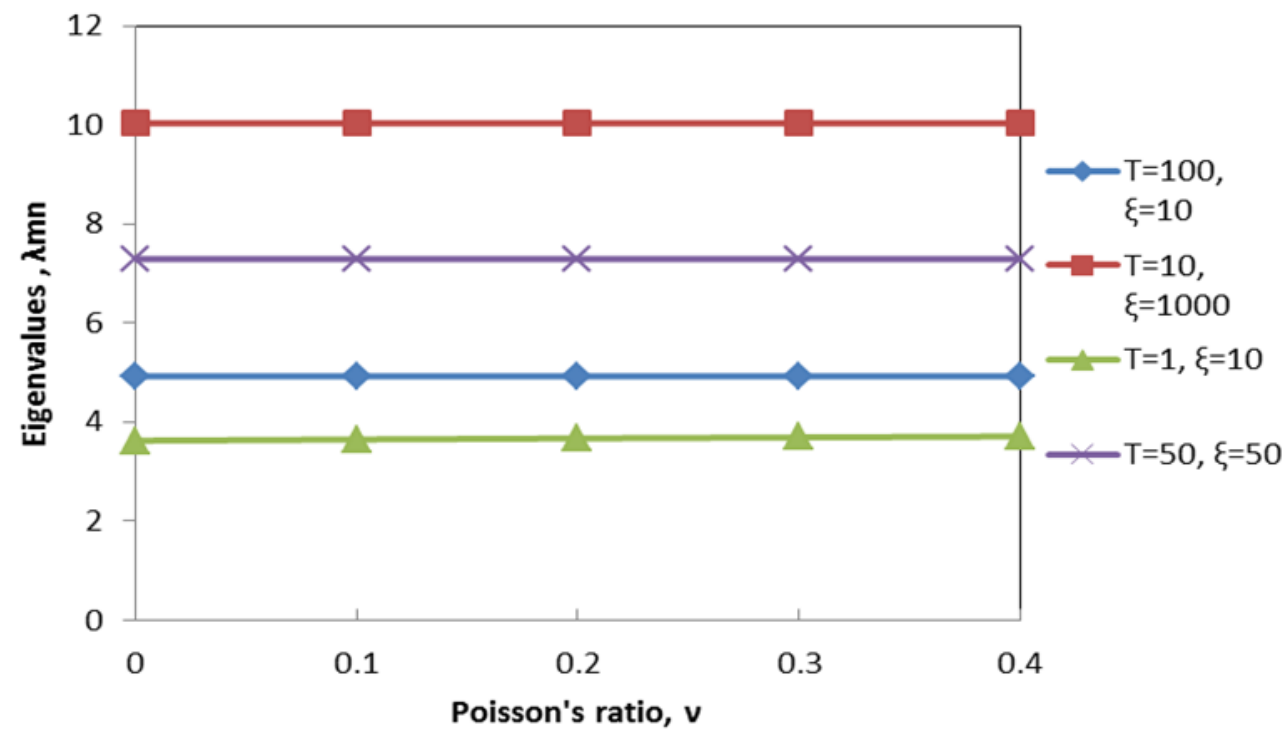

Figure 6. Effect of Poisson ratio, $v$ on eigenvalues, $\lambda_{m n}$.

\section{Conclusion}

This work deals with a method of computation of eigenvalues of flexural vibrations of a circular plate with translational edge supported and resting on Winkler foundation using a specifically written MATLAB code. The computed numerical results are presented in a tabular format to enable estimating the accuracy of approximate methods being used by other researchers for solving such problems. Twodimensional plots of eigenvalues are drawn for a wide range of translational and foundation stiffness ratios facilitating their use in design. From the numerical and graphical results presented in this paper, it can be easily observed that the eigenvalues remain constant only for a limited range of constraints specific to each vibration mode and then steeply increase with the increasing values of foundation stiffness ultimately converging towards a constant value. It is also observed that the influence of foundation stiffness ratio on eigenvalues is more predominant than that of translational stiffness ratio.

\section{Conflict of Interest}

The authors declare no conflicts of interest.

\section{Funding}

No funding was received for this research.

\section{References}

Ascione L, Grimaldi A (1984), Unilateral contact between a plate and an elastic foundation. Mechanica 19(3): 223-233.

Bhaskara RL, Kameswara RC (2009), Buckling of circular plates with a ring support and elastically restrained edge. Advances in Vibration Engineering 8(1): 61-69.

Bhaskara RL, Kameswara RC (2010), Buckling analysis of circular plates with elastically restrained edges and resting on internal elastic ring support. Mechanics Based Design of Structures and Machines 38(4): 440-452.

Bhaskara RL, Kameswara RC (2015), Vibrations of a rotationally restrained circular plate resting on a concentric rigid ring support. International Journal of Acoustics and Vibration 20(4): 220-225.

Celep Z (1988), Circular plate on tensionless Winkler foundation. Journal of Engineering Mechanics 114(10): 1723-1739.

Chang JY, Wickert JA (2001), Response of modulated doublet modes to traveling wave excitation. Journal of Sound and Vibration 242(1): 69-83.

Dempsey JP, Keer LM, Patel NB, Glasser ML (1984), Contact between plates and unilateral supports. Journal of Applied Mechanics 51(2): 324-328

Ghosh AK. (1997), Axisymmetric dynamic response of a circular plate on an elastic foundation. Journal of Sound and Vibration 205(1): 112-120.

Kang KH, Kim KJ (1996), Modal properties of beams and plates on resilient supports with 
rotational and translational complex stiffness. Journal of Sound and Vibration 190(2): 207-220.

Kim M, Moon J, Wickert JA (2000), Spatial modulation of repeated vibration modes in rotationally periodic structures. Journal of Vibration and Acoustics, Transactions of ASME 122(1): 62-68.

Kim KM, Kim MS (2001), Vibration of Beams with Generally Restrained Boundary Conditions using Fourier Series. Journal of Sound and Vibration 245(5): 771-784.

Leissa AW (1969), Vibration of plates (NASA SP-160). Office of Technology Utilization, Washington, DC.

Leissa AW (1993), Vibration of plates. Acoustical Society of America, Sewickley, PA.

Lokavarapu BRL, Chellapilla KR (2013), Fundamental buckling of circular plates with elastically restrained edges and resting on concentric rigid ring support. Frontiers of Mechanical Engineering 8(3): 291-297.

Lokavarapu BRL, Chellapilla KR (2015), Buckling of circular plate with foundation and elastic edge. International Journal of Mechanics and Materials in Design 11(2): 149156.

Rao CK, Rao LB (2009), Vibrations of elastically restrained circular plates resting on partial Winkler foundation. The Open Acoustics Journal 2: 68-74.

Rao CK, Rao LB (2016), Vibrations of circular plate supported on a rigid concentric ring with translational restraint boundary. Engineering Transactions 64(3): 259-269.
Salari M, Bert CM, Striz AG (1987), Free vibration of a solid circular plate free at its edges and attached to a Winbkler foundation. Journal off Sound and Vibration 118(1): 188-191.

Soedel W (1993), Vibrations of shells and plates. Marcel Dekker, Inc., New York.

Tseng JG, Wickert JA (1994), On the vibration of bolted plate and flange assemblies. Journal of Vibration and Acoustics, Transactions of ASME 116(4): 468-473.

Wang JTS, Lin CC (1996), Dynamic analysis of generally supported beams using fourier series. Journal of Sound and Vibration 196(3): 285-293.

Wang CY, Wang CM (2003), Fundamental frequencies of circular plates with internal elastic ring support. Journal of Sound and Vibration 263: 1071-1078.

Wang CY (2005), Fundamental frequency of a circular plate supported by a partial elastic foundation. Journal of Sound and Vibration 285(4-5): 1203-1209.

Weisman Y (1970), On foundations that react in compression only. Journal of Applied Mechanics 37: 1019-1030.

Winkler E. (1867), Die Lehre von der Elasticitaet and Festigkeit, Prag. Dominicus.

Yayli MÖ, Aras M, Aksoy S (2014), An efficient analytical method for vibration analysis of a beam on elastic foundation with elastically restrained ends. Shock and Vibration 2014: 17.

Zheng XJ, Zhou YH (1988), Exact solution of nonlinear circular plate on elasticfoundation. Journal of Engineering MechanicsASCE 114: 1303-1316. 